This item was submitted to Loughborough's Research Repository by the author.

Items in Figshare are protected by copyright, with all rights reserved, unless otherwise indicated.

\title{
Probabilistic assessment of enhanced frequency response services using real frequency time series
}

PLEASE CITE THE PUBLISHED VERSION

https://doi.org/10.1109/SIELA.2018.8447080

PUBLISHER

(C) IEEE

VERSION

AM (Accepted Manuscript)

LICENCE

CC BY-NC-ND 4.0

\section{REPOSITORY RECORD}

Sanchez, F., Francisco M. Gonzalez-Longatt, and Dimitar Bogdanov. 2019. "Probabilistic Assessment of Enhanced Frequency Response Services Using Real Frequency Time Series”. figshare.

https://hdl.handle.net/2134/33488. 


\section{Probabilistic Assessment of Enhanced Frequency Response Services Using Real Frequency Time Series}

\author{
F. Sanchez \\ The Wolfson School: Electronic, \\ Electrical, and Systems Engineering \\ Loughborough University \\ Loughborough, UK \\ F.Sanchez@Lboro.ac.uk
}

\author{
F. Gonzalez-Longatt \\ The Wolfson School: Electronic, \\ Electrical, and Systems Engineering \\ Loughborough University \\ Loughborough, UK \\ fglongatt@fglongatt.org
}

\author{
D. Bogdanov \\ The Technical University of Sofia, \\ Faculty of electrical engineering, \\ 18, Kl. Ohridski Blvd. \\ 1000 Sofia, Bulgaria \\ dbogdanov@tu-sofia.bg
}

\begin{abstract}
This paper presents a probabilistic assessment of the novel enhanced frequency response (EFR) service in the Great Britain (GB) transmission system. Real frequency measurements with one-second resolution, released by National Grid (NG) corresponding to the years 2014 and 2015, are used for the performance assessment. Initially, the frequency quality is evaluated against Security and Quality of Supply Standards (SQSS) of NG. Afterwards, battery energy storage systems (BESSs) with different power to energy ratios have been modelled and fed with the GB frequency time-series while providing two variants of EFR service. Then, a state of charge (SOC) management algorithm is implemented for comparison purposes. Finally, cumulative probability distribution functions (CDF) are created to analyse the performance of the BESS. The high utilization rates obtained for one the EFR services suggests that for the provision of EFR to be profitable for the providers, the service should refocus towards the post-fault or frequency containment region.
\end{abstract}

Keywords- Enhanced Frequency Response, Battery Energy Storage System, Frequency Regulation, Frequency Containment.

\section{INTRODUCTION}

The steady increase in penetration of variable renewable energies poses a challenge for system operators (SOs) who have an obligation to maintain the frequency of the power system inside a tight range. The intermittency of the resource coupled with the fact that most renewable energy sources are connected to the system via electronic power converters which do not contribute to the total inertia, make the system more vulnerable. Significant research efforts are being made to improve the resiliency in low inertia systems. Technologies such as the use of conventional plants as synchronous compensators to provide inertia [1], emulated inertia [2] from wind turbines [3], [4] and battery energy storage systems (BESS) providing synthetic inertia [5], are increasingly being adopted by SOs. Frequency regulation services (FRSs) provided by BESSs are fast becoming a key instrument in support of grid stability [6], [7] with estimations of up to $10.7 \mathrm{GW}$ of connected battery storage by the year 2050 [8]. Their usefulness stems from their high power to energy ratio as well as its high ramp rates, which allow for a fast response. Recently, a new mechanism contributing to frequency response was introduced in the GB [9]. This fast- acting mechanism, termed Enhanced Frequency Response (EFR), is aimed for the very fast energy storage system as BESS, flywheel and supercapacitors.

The objective of this paper is to perform a probabilistic assessment of the BESS providing the EFR service by using time-series of frequency measurements taken from the GB system. Initially, a statistical analysis of the frequency data released by NG (years 2014-15) is presented, considering the point of view of an asset providing EFR services. Then, an analysis to assert the adequacy of the EFR parameters is presented to determine if energy management strategies are essential for BESSs providing the service.

\section{ENHANCED FREQUENCY RESPONSE (EFR) SERVICE}

The nominal frequency of the electricity supply in GB is 50 Hz. In normal circumstances, the frequency is to be maintained within $\pm 1.0 \%$ of its nominal value, in the range between 49.5 $50.5 \mathrm{~Hz}$. Still, the SO manages the frequency within the more stringent operational limits of 49.8 and $50.2 \mathrm{~Hz}$. In abnormal circumstances, such as a loss of generation equal to the infrequent infeed loss $(1,800 \mathrm{MW})$, the maximum frequency deviation is limited to $0.8 \mathrm{~Hz}$. However, the $\mathrm{SO}$ is required to restore it to the statutory range within 60 seconds and to the operative range within 10 minutes [10]. Frequencies at or below $48.8 \mathrm{~Hz}$ trigger the National Low-Frequency Demand Disconnection (LFDD) scheme which disconnects demands by blocks to avoid a power system shutdown.

The BESS must deliver active power to the grid in proportion to the system frequency outside the deadband with less than $1.0 \mathrm{~s}$ delay when they are providing EFR. The deadband corresponds to the frequency range between points $f_{W}$ and $f_{X}$ (see details in Fig. 1 and Table ITABLE I), and inside this region, the BESS is able to manage its SOC. The absorbed or delivered power in this region is limited to $9.0 \%$ of the BESS nominal power. The output of the BESS is bounded at all times by a lower and upper profile that converges at frequencies $f_{V}$ and $f_{Y}$. Frequencies larger than $f_{Y}$ or lower than $f_{V}$ are considered to be post-fault so, in this range, the output characteristic prioritizes frequency control and hence, there is no possibility of SOC management. Currently, there are two types of EFR services, namely Service 1 and Service 2. Service 1 has a larger 
deadband than Service 2. Therefore, it is less sensitive to frequency deviations [9]. In terms of the service duration, the BESS is required to deliver $\left(f \leq f_{U}\right)$ or absorb $\left(f \geq f_{Z}\right)$ its nominal power for at least 15 minutes. This equates to a minimum nominal capacity to nominal power ratio of $0.5 \mathrm{~h}$, or equivalently, it must be able to discharge from maximum to minimum capacity in 30 mins. Ramp rates for power delivery or absorption are limited so as not to cause detrimental frequency issues. The effect of the ramp rate limits is not considered in this paper.

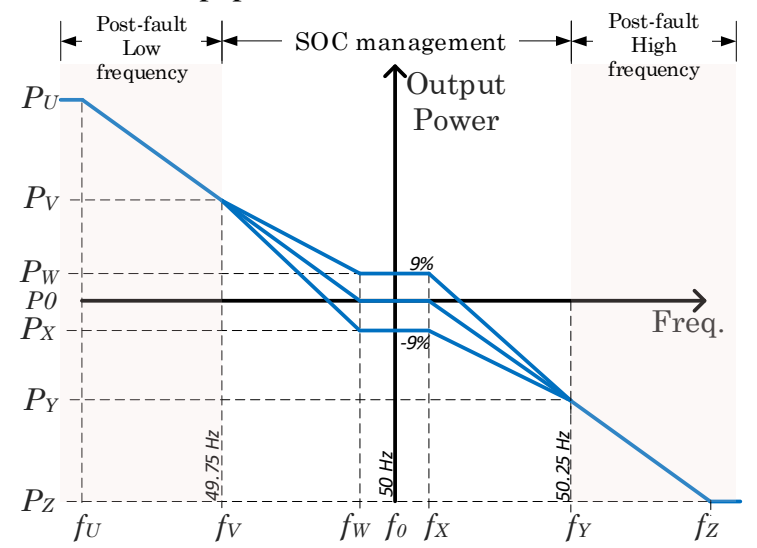

Fig. 1. Generic power-frequency $(p-f)$ characteristic of the EFR service.

TABLE I. EFR PARAMETERS FOR SERVICE 1 AND SERVICE 2.

\begin{tabular}{|c|c|c|}
\hline Parameter & EFR Service 1 & EFR Service 2 \\
\hline$P_{U}$ & $100 \%$ & $100 \%$ \\
\hline$P_{V}$ & $44.44 \%$ & $48.45 \%$ \\
\hline$P_{Y}$ & $-44.44 \%$ & $-48.45 \%$ \\
\hline$P_{Z}$ & $-100 \%$ & $-100 \%$ \\
\hline$f_{u}$ & $49.5 \mathrm{~Hz}$ & $49.5 \mathrm{~Hz}$ \\
\hline$f_{w}$ & $49.95 \mathrm{~Hz}$ & $49.985 \mathrm{~Hz}$ \\
\hline$f_{x}$ & $50.05 \mathrm{~Hz}$ & $50.015 \mathrm{~Hz}$ \\
\hline$f_{z}$ & $50.5 \mathrm{~Hz}$ & $50.5 \mathrm{~Hz}$ \\
\hline
\end{tabular}

\section{Statistical ANALysis OF GB FREQUENCY TIME-SERIES}

Frequency data from January 2014 to December 2015, with a resolution of 1.0 second, has been released by NG with the purpose of analysis by the providers of EFR [9]. The subsequent analysis has been carried out using the complete data at onesecond resolution. Before processing, the consistency of the data was checked, and duplicate values were removed. The proportion of erroneous to valid data was found to be negligible. No frequency excursions outside the statutory range during the years analysed were found. The frequency was found to be outside the operative range for 369.3 mins overall in the twoyear period studied and considering that the yearly limit is 15,000 mins, this constitutes evidence of excellent control. Similarly, the number of frequency excursions outside the operative range with a duration of at least 60 seconds was 95 combined between both years with a yearly limit of 1,500. The daily standard deviation was below its limit with just one exception in early 2015 (which will be discussed below). An assessment of the frequency in terms of its quality target parameters is shown in Table II.

The GB system frequency for the years studied exhibits a bell-shaped curve with peaks slightly above and below the nominal frequency of $50 \mathrm{~Hz}$ for both years studied (see Fig. 2). Table III presents summary statistics for the frequency during both years studied. The standard deviation for 2014 was 54.462 $\mathrm{mHz}$, and for 2015 it was $54.396 \mathrm{mHz}$. The frequency was maintained inside the operative range for $99.96 \%$ of 2014 and $99.97 \%$ of 2015 . Moreover, the frequency remained inside the statutory range for $100 \%$ of the period studied.

TABLE II. FREQUENCY QUALITY TARGET PARAMETERS AND ASSESSMENT.

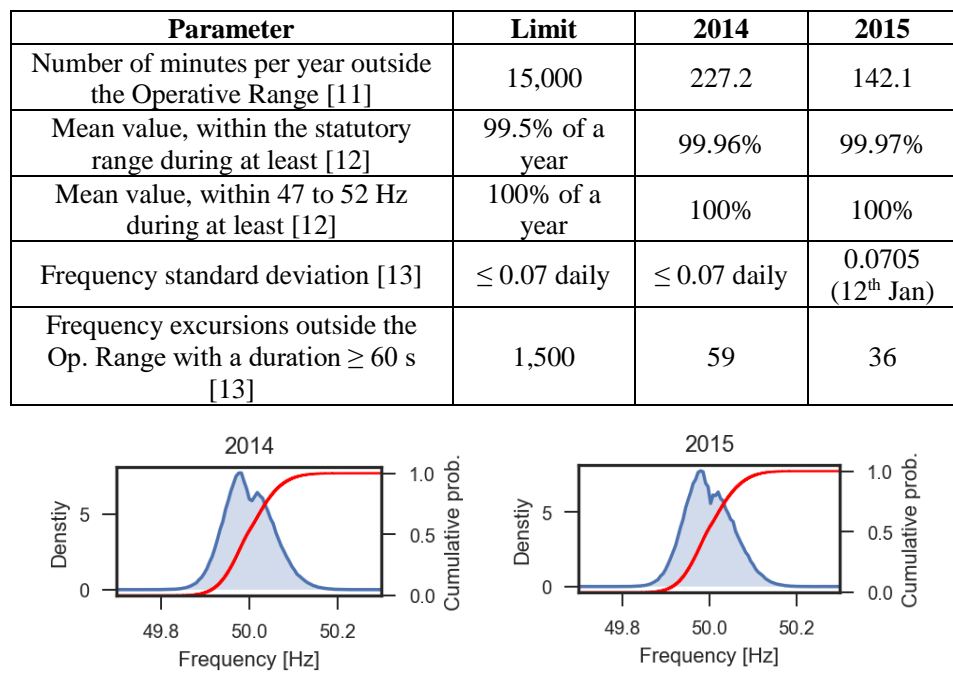

Fig. 2. Density of frequency and cumulative probability for 2014 and 2015.

TABLE III. SUMMARY STATISTICS FOR THE FREQUENCY DURING 2014 AND 2015 .

\begin{tabular}{|c|c|c|}
\hline Statistic indicator & $\mathbf{2 0 1 4}$ & $\mathbf{2 0 1 5}$ \\
\hline Count & $31,536,000$ & $31,536,000$ \\
\hline Mean [Hz] & 49.9997 & 49.9997 \\
\hline Standard Deviation [Hz] & 0.054462 & 0.054396 \\
\hline Minimum [Hz] & 49.5560 & 49.5950 \\
\hline Maximum [Hz] & 50.3190 & 50.3250 \\
\hline
\end{tabular}

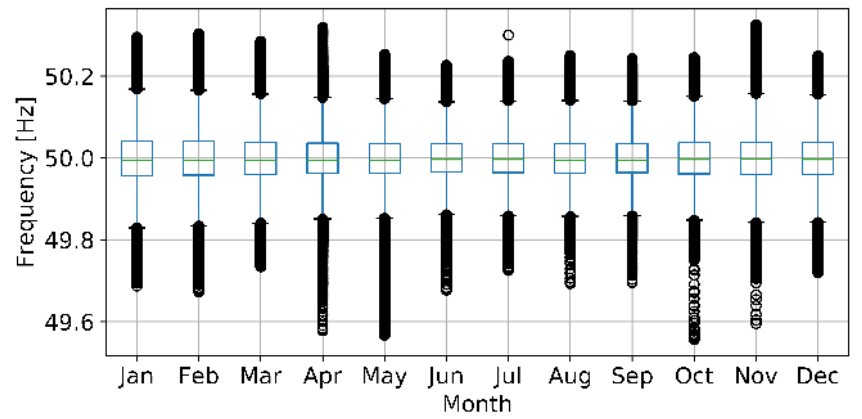

Fig. 3. Boxplot of the monthly frequency data for 2014 and 2015 combined.

Fig. 3 shows a box plot of the GB system frequency for the months of the years 2014 and 2015 combined. In general, the behaviour of the frequency is similar throughout the year which is evidence of good control measures. Slightly lower frequency dispersion is experienced in the months of June to September due to the overall demand decrease experienced in this period [14].

\section{A. Time Kept Ratio}

The Time Kept Ratio (TKR) is a widely used index to gauge frequency quality in a specified area. It is defined in (1) as the 
sum of the time that the frequency is inside the specified range divided by the total time in the period.

$$
\operatorname{TKR}(\%)=\frac{100}{N} \sum_{i=1}^{N} A_{i}
$$

Where $N$ represents the total number of measurements in the sample, and the binary function $A_{i}$ is equal to 1.0 when the frequency is in the specified range and 0.0 otherwise. The average yearly $T K R$ for the operative and the statutory range is shown in TABLE IV. The frequency was within the statutory range for the whole duration of the studied period (quality target parameters are shown in TABLE II).

TABLE IV. AVERAGE TKR FOR 2014 AND 2015.

\begin{tabular}{|c|c|c|}
\hline Year & $\begin{array}{c}\text { TKR operative range } \\
( \pm \mathbf{0 . 2} \mathbf{~ H z})\end{array}$ & $\begin{array}{c}\text { TKR statutory range } \\
(\mathbf{\pm 0 . 5} \mathbf{~ H z})\end{array}$ \\
\hline 2014 & $99.9568 \%$ & $100 \%$ \\
\hline 2015 & $99.9729 \%$ & $100 \%$ \\
\hline
\end{tabular}

\section{B. Standard deviation}

The daily frequency standard deviation was below the limit throughout 2014 and, as shown in Fig. 4(a) during most of 2015. However, closer inspection of the figure shows that it exceeded the daily limit on January $12^{\text {th }}, 2015$. This day, between 07:30 $\mathrm{h}$ and 08:44 $\mathrm{h}$ the frequency was outside the operative limits for 442 seconds as presented in Fig. 4(b) presumably due to an unexpected demand loss.

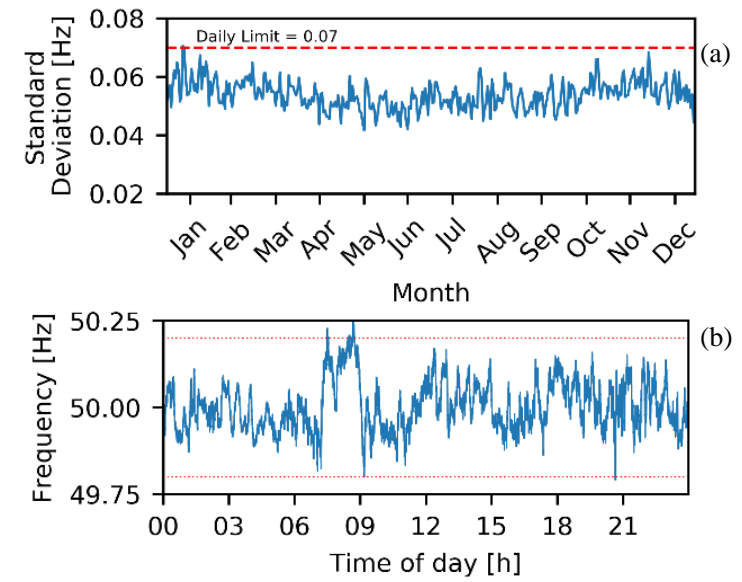

Fig. 4 (a) Average daily standard deviation for 2015. (b) Frequency on Jan $12^{\text {th }}, 2015$. The red dotted lines highlight the operative range.

\section{BESS PROVIDING EFR SERVICES}

The following convention in the power/energy flow at the BESS is assumed: (a) $P_{i}>0$ : Power flows from the BESS to the grid. (b) $P_{i}<0$ : Power flows from the grid to the BESS.

The energy level of the BESS at the end of any interval $j$ depends on the energy exchanged in all the previous intervals as is shown in (2), where $E_{0}$ represents the initial stored energy, $P_{i}$ is the BESS output power at the $i$-th interval, and $\Delta T$ is the interval duration. The SOC at the end of the $j$-th interval is computed as in (3) where $\hat{P}_{i}$ is the BESS power in per unit. This considers the charging and discharging efficiencies as $\gamma_{i}=\eta_{\text {charge }}$ when the battery is charging and $\gamma_{i}=1 / \eta_{\text {discharge }}$ when it is discharging.

$$
\begin{gathered}
E_{j}=E_{0}-\Delta T \sum_{i=1}^{j} P_{i} \\
S O C_{j}=S O C_{0}-\frac{\Delta T}{R_{B E S S}} \sum_{i=1}^{j} \gamma_{i} \hat{P}_{i}
\end{gathered}
$$

The ratio of nominal capacity to nominal power of the BESS is defined as $R_{B E S S}=C_{n} / P_{n}$.

The case where the SOC is not managed and follows the middle EFR reference line is useful to establish the minimum BESS which would be able to supply the frequency services for a given period. For illustrative purposes, Fig. 5 shows a period of two weeks in February 2015. For this study, the charging and discharging efficiencies of the BESS were set at 95\% [15], and the initial SOC was set at 0.5 . Remarkably, given the symmetry of the frequency in GB, the BESS would be able to provide Service 1 for over a week before saturating its SOC to the maximum, which for simplicity here is taken as 1.0. The same BESS, providing Service 2 would deplete its SOC within the first couple of days. A large battery with an $R_{B E S S}$ of 1.64 would be necessary to provide service 1 during this period without managing the SOC ( $R_{B E S S}$ of 1.75 for Service 2$)$.

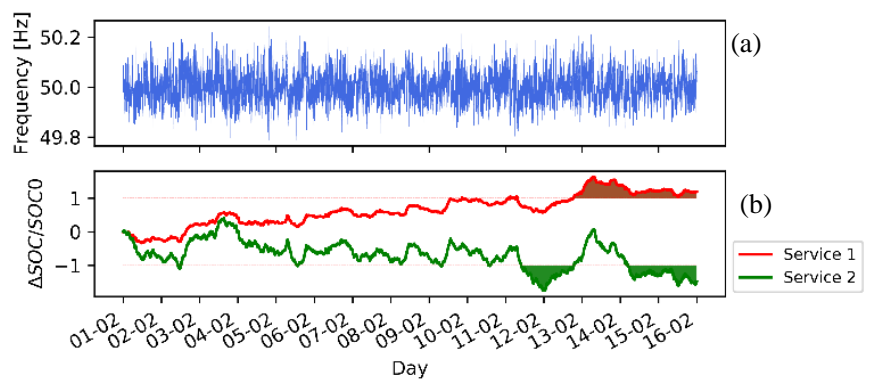

Fig. 5. (a) Frequency. (b) State of charge deviation for BESS providing EFR Service 1 and Service 2.

By managing the SOC when the frequency is inside the deadband, a smaller battery can provide both services. In this case, the objective is to bring the SOC to a target range. Simulations are presented with a simple control scheme which works as follows. When the frequency is inside the deadband, and the SOC is lower than the minimum target, the BESS is instructed to absorb power from the grid until the SOC reaches its minimum target value. Conversely, if the SOC is higher than the maximum target, the BESS is instructed to inject power to the grid until the SOC reaches its maximum target value. Outside the deadband, the power at which the BESS manages its SOC is proportional to the deviation between the current and the desired SOC (see Fig. 1). The SOC and output power of an asset providing Service 2 is shown in Fig. 6 (a). The SOC target range has been set between 0.45 and 0.55 . The control scheme manages to keep the SOC inside the target range for $83.2 \%$ of the time and the output of the asset moves between -0.25 and 0.25 of its nominal power during $99.1 \%$ of the time as shown in Fig. 6 (b) and (c) respectively.

Fig. 7 shows the cumulative probability of the SOC for assets of different sizes whilst providing both EFR services. The SOC was managed as above. As expected, the probability that the SOC remains inside the target range is higher for assets providing Service 1 than for assets providing Service 2. 
However, it is shown that even small assets $\left(R_{B E S S}=0.25 \mathrm{~h}\right)$ can maintain its SOC inside its target range for at least $71.6 \%$ of the time while providing the more stringent Service 2; and this figure increases to $97.8 \%$ for larger assets $\left(R_{B E S S}=2.0 \mathrm{~h}\right)$.
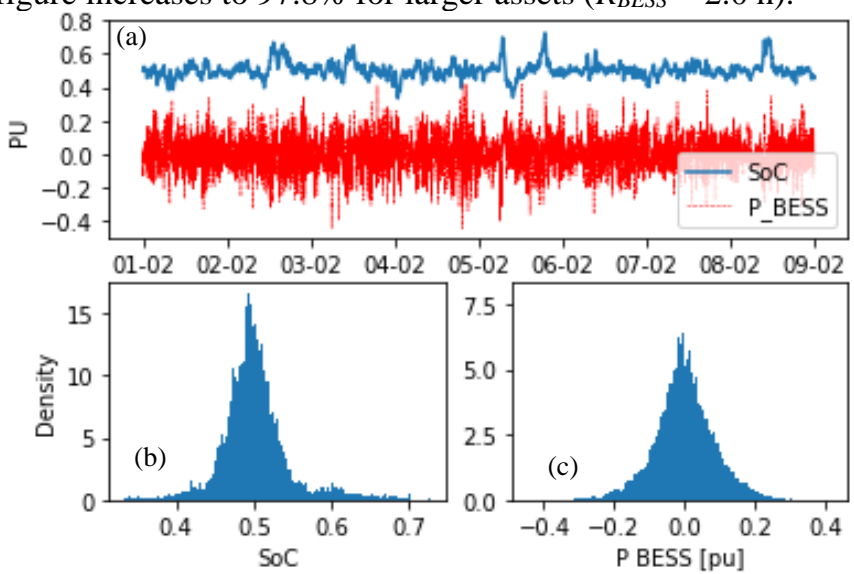

Fig. 6. BESS providing EFR Service 2 during a week. (a) State of charge and output BESS power. (b) Output power histogram. (c) SOC histogram.

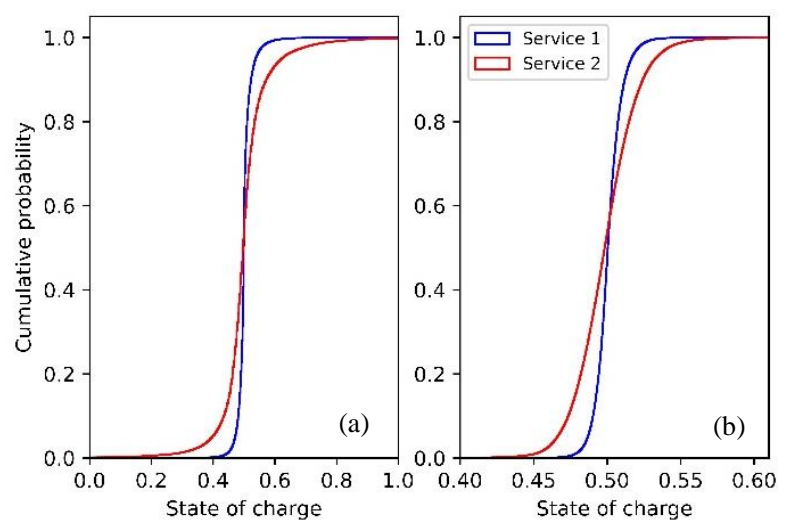

Fig. 7. Cumulative probability for the SOC of the managed BESS. (a) $R_{B E S S}=$ $0.25 \mathrm{~h}$. (b) $\mathrm{R}_{\mathrm{BESS}}=2.0 \mathrm{~h}$

\section{CONCLUSIONS}

This research has shown that the frequency in GB is generally well maintained. The historical frequency was benchmarked against different quality target parameters and was found to comply. Adequacy of frequency control was also evidenced by metrics such as the Time Kept Ratio and the daily standard deviation, and although their values were found to be within the accepted range, it was found that these metrics experience high seasonality.

The operative differences between the two variants of EFR are significant given the frequency profile of GB. An asset providing service 1 would have a low utilization since it would be activated for a little over 10 hours per year and around $95 \%$ of this time it would be responding to under-frequency events.
On the other hand, an asset providing service 2 would be activated over 6,250 hours per year or around $71 \%$ of the time. The effect that these different utilization profiles have on the cycle life of the BESS is expected to be significant and constitutes a topic for further research. This suggests that for the provision of EFR to be profitable for the providers, the frequency deadband for service 2 should be increased which would move the EFR product away from the frequency regulation market and more towards the post-fault region or frequency containment. These findings strengthen the idea that an adequate SOC management scheme is essential for the provision of EFR. With such scheme, it is possible to supply the service continuously, however, without a SOC management scheme, the BESS would experience a saturation or depletion of its capacity in a few days.

\section{REFERENCES}

[1] H. T. Nguyen, G. Yang, A. H. Nielsen, and P. H. Jensen, "Frequency stability improvement of low inertia systems using synchronous condensers," in 2016 IEEE International Conference on Smart Grid Communications, SmartGridComm 2016, 2016, pp. 650-655.

[2] H. R. Chamorro, N. R. Malik, F. Gonzalez-Longatt, and V. K. Sood, "Evaluation of the synthetic inertia control using active damping method," in 2017 6th International Conference on Clean Electrical Power (ICCEP), 2017, pp. 269-274.

[3] Q. Gao and R. Preece, "Improving frequency stability in low inertia power systems using synthetic inertia from wind turbines," 2017 IEEE Manchester PowerTech, pp. 1-6, 2017.

[4] F. M. Gonzalez-Longatt, "Impact of emulated inertia from wind power on under-frequency protection schemes of future power systems," J. Mod. Power Syst. Clean Energy, vol. 4, no. 2, pp. 211-218, Apr. 2016.

[5] S. M. Alhejaj and F. M. Gonzalez-Longatt, "Investigation on grid-scale BESS providing inertial response support," in 2016 IEEE International Conference on Power System Technology, POWERCON 2016, 2016.

[6] M. Müller et al., "Evaluation of grid-level adaptability for stationary battery energy storage system applications in Europe," J. Energy Storage, vol. 9, pp. 1-11, 2017.

[7] C. Brivio, S. Mandelli, and M. Merlo, "Battery energy storage system for primary control reserve and energy arbitrage," Sustain. Energy, Grids Networks, vol. 6, pp. 152-165, 2016.

[8] National Grid, "Future Energy Scenarios," 2017.

[9] National Grid, "Enhanced Frequency Response," vol. 44, no. 0, pp. 1-29, 2016.

[10]National Grid, E. Transmission, E. Act, G. Britain, and P. Act, "The grid code," no. 5, 2015.

[11]ENTSO-E, "Network Code on Load-Frequency Control and Reserves," vol. 6, no. February 2012, pp. 1--68, 2013.

[12]BSi, "BS EN 50160-2010+A1-2015: Voltage characteristics of electricity supplied by public electricity networks," no. December, 2010.

[13] National Grid, "National Electricity Transmission System Security and Quality of Supply Standard," vol. Ver. 2.3, no. March, p. 59, 2017.

[14] National Grid, "Summer Outlook Report," no. October, 2017.

[15]B. Lian, A. Sims, D. Yu, C. Wang, and R. W. Dunn, "Optimizing LiFePO4 Battery Energy Storage Systems for Frequency Response in the UK System," IEEE Trans. Sustain. Energy, vol. 8, no. 1, pp. 385-394, 2017. 